\title{
Effect of Loom Speed on Warp Contraction Percentage of Cotton Fabric
}

\author{
Saurbh P Savant, Sujit S Gulhane*, Ranjit N Turukmane and Amarjeet M Daberao \\ Center for Textile Functions, SVKM's NMIMS, India \\ *Corresponding author: Sujit S Gulhane, Center for Textile Functions, SVKM's NMIMS, India
}

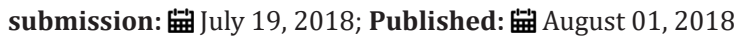

\begin{abstract}
The calculation of raw material requirement and its utilization for given set of production is an important factor of every industry. In woven fabric manufacturing it is required to measure accurate length of the warp required to produce ordered length of the fabric. Many times actual fabric produced from prepared warp is more or less. In weaving many factors decide the length of war consumed for given set of fabric length such as, warp and weft count, EPI, PPI, loom rpm, weaving tension, yarn softness and stiffness etc. This project aims to find the effect of loom speed on the warp contraction percentage of Plain, Twill and Satin weave fabric.
\end{abstract}

Keywords: Warp contraction percentage; Loom speed; Weaving production planning

\section{Introduction}

The production planning of the weaving industry like other industries plays an important role in making profits. Any failure in production planning rises out of the observation that many mills suffer losses, or fail to attain maximum possible profits because of improper planning of production and inventory at critical [1]. In weaving industry as per the requirement of the fabric length to be produced or dispatched back calculations are made to decide the length of the sized beam, set length of the warp beam and total warp cone yarn required. These calculations are based on the percentage of west in every stage of the manufacturing and the warp crimp percentage. But still it is observed that many times the expected fabric length to be produced does not match the planning calculation. This happens due to more wastage in the manufacturing process than considered values [2]. Apart from this the machine process parameters like tension in the warp in warping and sizing, loom speed and other process parameters of the loom will also affects warp consumption. In modern loom shed with advance looms, the speed of looms were set at 800 to 1000 rpm depending up on the count and width of the fabric. Same sort of the fabric running on different looms are set to run at various speed to reduce loom stoppages and fabric defects. Many times looms are set to run at lower speed due to weavers beam shortages or to prolonged the time of beam doff due to shortage of man power for beam doffing. This variation of the loom speed not only results in variation of production per loom but also cause difference in the warp contraction percentage. This difference in warp contraction of looms leads to variation in the length of fabric produced from the same length of the warp, which will be a cause for production a fabric more or less than the expected length of the fabric. This is the sever problem which weaving industry faces consistently, Thus it is important to find the proper solution for this problem [3]. This study is conducted to find out the effect of loom speed on contraction percentage for Plain, Twill and Satin weave fabric. The findings of this study will help in production planning reduce the variation in planned length of the fabric and actual fabric produced in the loom shed. The Contraction percentage is defined as the mean difference between the warp length and the length of fabric produced from same warp beam. When warp and weft yarns interlace in fabric they follow a wavy or corrugated path. The contraction percentage is expressed as a percentage of beam length to the difference between the lengths of war pan length of the fabric produced as show in following formula.

Contraction $\%=$ Length of the warp - length of the fabric X 100

$$
\text { Length of the warp }
$$

The woven fabric with plain, twill and satin weave was produced on the loom at different speed of the loom. The warp contraction $\%$ for each weave at different speed ranging from 600rpm to 1000rpm with an interval of 50rpm was noted [4]. This data is then analyzed to find out the effect of loom speed on warp contraction percentage for different speed.

\section{Material and Experiment}

This study was conducted at Yogi Co-Tex limited, weaving division, Shirpur Textile Park on Picanol Omni Plus 800 air jet loom with electronic dobby. The plain weave 10 fabric samples were 
weaved at loom rpm of $800,825,850,875,900,925,950,975,1000$ and 1025 . These fabric samples were produced from 10 meter warp sheet for each sample. Then each fabric sample was measured for its length to calculate warp contraction percentage. Similar method is used to measure warp contraction percentage of the twill and satin weave fabric on the same loom without changing loom setting except loom speed and fabric weave [5]. The experimental data shows that there is a significant difference in the consumption rate in the warp length per unit fabric produced at different speed of the loom (Table 1).

Table 1: Sort selected for study effect of loom speed on warp contraction \%.

\begin{tabular}{|c|c|c|c|c|c|c|}
\hline Sort No & Warp Count & weft Count & EPI & PPI & Fabric Width & Weave \\
\hline 14010 & 40 & 40 & 132 & 72 & 63 & plain \\
\hline 14044 & 40 & 40 & 132 & 72 & 63 & twill \\
\hline 14009 & 40 & 40 & 132 & 72 & 63 & satin \\
\hline
\end{tabular}

\section{Result and Discussion}

The total 30 fabric samples were produced and measured for its length to calculate the warp contraction percentage. The warp

Table 2: Warp contraction percentage of the fabric samples. contraction percentage is calculated by the formula

Contraction \% = Length of the warp - length of the fabric X 100 Length of the warp

\begin{tabular}{|c|c|c|c|c|}
\hline \multirow{2}{*}{ Sample No } & \multirow{2}{*}{$\begin{array}{c}\text { Loom Speed } \\
\text { (RPM) }\end{array}$} & Plain & \multicolumn{3}{|c|}{ Warp Contraction Percentage } \\
\cline { 2 - 5 } & & Sort no 14010 & Swill & Sort no 14044 \\
\hline 1 & 800 & 12.47 & 10.47 & 9.45 \\
\hline 2 & 825 & 11.88 & 9.46 & 8.74 \\
\hline 3 & 850 & 11.56 & 8.45 & 7.11 \\
\hline 4 & 875 & 11.12 & 7.69 & 6.79 \\
\hline 5 & 900 & 10.92 & 7.12 & 6.44 \\
\hline 6 & 925 & 10.68 & 7.32 & 7.46 \\
\hline 7 & 950 & 10.33 & 7.88 & 7.93 \\
\hline 8 & 975 & 9.94 & 8.03 & 7.42 \\
\hline 10 & 1000 & 9.66 & 8.22 & 7.78 \\
\hline
\end{tabular}

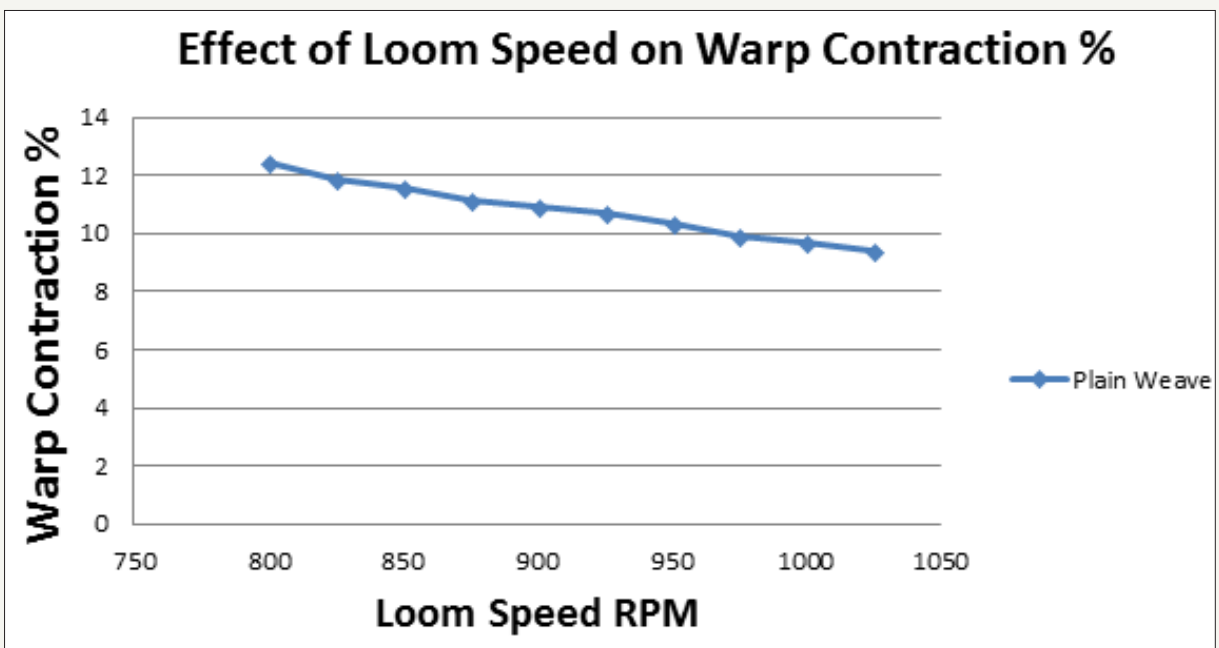

Figure 1: Warp contraction percentage at various loom speeds for plain weave.

Following table shows the resultant warp contraction percentage obtained while producing fabric samples (Table $2 \&$ Figure 1).

\section{Observation-I}

It is observed from the above graph the warp contraction percentage reduces from 12.47 to 9.37 . The warp contraction 
percentage decreases with increase in speed of the loom [6]. The reduction in warp contraction percentage is due to rise in the tension of the warp sheet. This tension restricts warp yarn to bend around the weft and reduces wavy path of the warp around the weft. Thus increment in the loom speed increases tension in the warp, which results into the decrease in the warp contraction percentage. Initially with increase in loom speed shows higher rate of reduction in warp contraction, this rate of reduction in warp contraction percentage with increase in loom speed reduces subsequently. At the speed of loom more than $950 \mathrm{rpm}$ the warp contraction percentage become more or less constant (Figure 2).

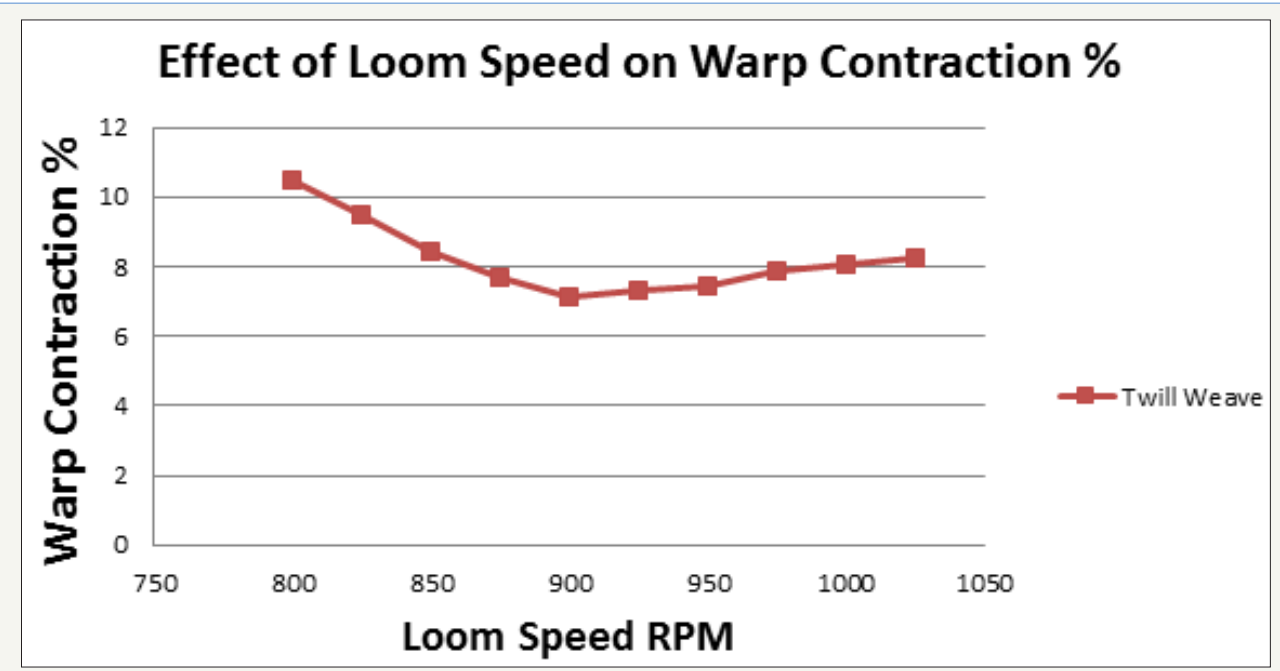

Figure 2: Warp contraction percentage at various loom speeds for twill weave.

\section{Observation-II}

It is observed from the graph 2 the trend of warp contraction shows with increase in speed of the loom warp contraction $\%$ goes on decreasing up to 900rpm further increase in loom speed shows slight rise in the warp contraction percentage. The cause for decrease in the warp contraction percentage is similar to that in the case of plain weave. The fabrics samples weave at speed more than 900rpm shows rise in the contraction percentage. This rise in contraction percentage is doe to increase in the beat-up force with increase in loom speed [7]. Higher beat up force push last inserted weft closer to the fell of the cloth. The loom speed higher than 900rpm shows rise in beat-up force which overcome the impact of rise in warp tension due to rise in loom speed and causes warp yarns to bend over and under the weft yarn (Figure 3).

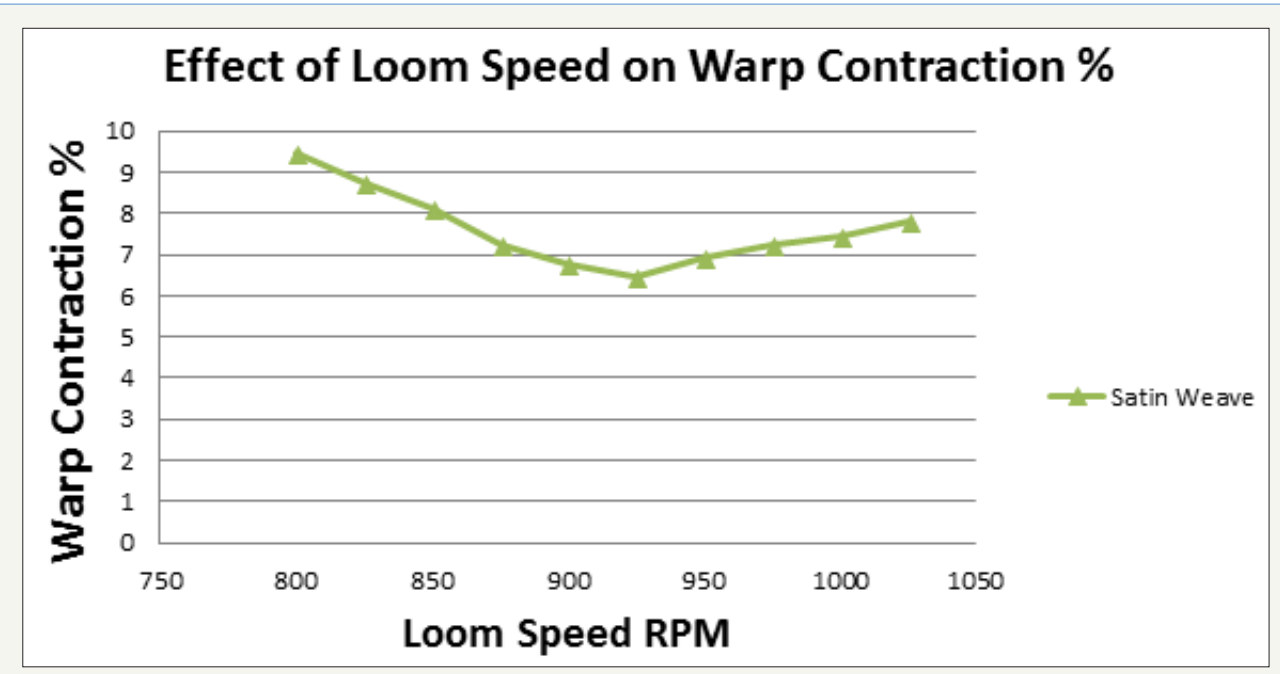

Figure 3: Warp contraction percentage at various loom speeds for satin weave.

\section{Observation-III}

It is observed from the graph 2 the trend of warp contraction shows with increase in speed of the loom warp contraction \% goes on decreasing up to 900rpm further increase in loom speed shows slight rise in the warp contraction percentage. The cause for decrease and rise in the warp contraction percentage is similar to that in the case of twill weave. The fabrics samples weave at speed more than 925rpm shows rise in the contraction percentage. The loom speed higher than $925 \mathrm{rpm}$ shows rise in beat-up force which overcome the impact of rise in warp tension due to rise in loom speed and causes warp yarns to bend over and under the weft yarn [8]. 


\section{Conclusion}

The experimental results shows that the loom speeds have significant impact on the warp contraction percentage. Thus while considering warp contraction percentage in for planning of warp set length loom speed at which fabric will be produced need to considered. The consideration of loop speed and other weaving parameters will make warp consumption calculation for given length of the fabric more real to the actual fabric produced in the loom shed. The loom speed is also need to be standardized with respect to the length of the fabric produced per unit length of the warp sheet. As loom speed affects war contraction percentage it will also affects the quality of the fabric weaved on the loom. The quality of the fabric is depend on the structure of the fabric, fabrics produced with different contraction percentage shows variation in there structures. The fabrics will shows uninformed properties in terms of shrinkage, elasticity, GSM, etc in further processing and garmenting. Thus weaving industry should run all looms with same speed weaving a same sort of fabric to produce a fabric with uniform quality.

\section{References}

1. Karacapilidis, Nikos I, Costas PP (1996) Production planning and control in textile industry: A case study. Computers in industry 30(2): 127-144.

2. Maqsood, Muhammad, Tanveer H, Yasir N, Khubab S, et al. (2015) Prediction of warp and weft yarn crimp in cotton woven fabrics. The Journal of the Textile Institute 106(11): 1180-1189.

3. Yukhin SS, Ye AY (1996) A theoretical consideration of the warp and weft contractions in woven fabrics. Journal of the Textile Institute 87(3): 532541 .

4. Afroz, Farhana, Ayesha S (2014) Effect of warp yarn tension on crimp\% in woven fabric. European Scientific Journal 10(24).

5. Jiraskova, Petra, Moučková E (2010) New method for the evaluation of woven fabric unevenness. AUTEX Research Journal 10(2): 49-54.

6. Olsen, Richard P (1978) The textile industry: An industry analysis approach to operations management. Free Press, India.

7. Alamdar Yazdi A (2004) Weave structure and the skewness of woven fabric. Research Journal of Textile and Apparel 8(2): 28-33.

8. Alkadi N, Karnoub A (2015) The effect of warp and weft variables on fabric's shrinkage ratio. Journal of Textile Science \& Engineering 5(2): 1.
Creative Commons Attribution 4.0 International License

For possible submissions Click Here

\section{Submit Article}

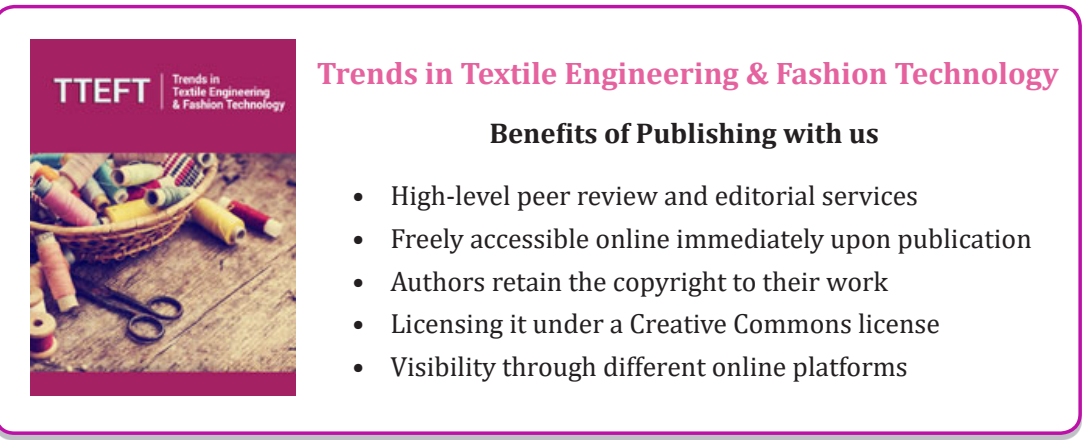

